\title{
NILAI ESTETIKA DAN CITA RASA MAKANAN DALAM PENYAJIAN MAKIZUSHI MUSIM GUGUR PADA TV CHAMPION JEPANG
}

\author{
Theng Anita Christianawati
}

3122011343@mhs.dinus.ac.id

Universitas Dian Nuswantoro

\begin{abstract}
This research discusses the aesthetic value and taste of the food served in autumn makizushi as shown in TV Champion Japan. It aims to find out the aesthetic value and taste of autumn makizushi, because there are several types of sushi based on the season they are served. The video data were taken from the first episode of Sushi King series of TV Champion, produced by TV Tokyo Japan. The type of this study is descriptive qualitative. The result of the study show that there are several characteristics of aesthetically served makizushi, i.e.; unity, symmetry, harmony, balance and contrast. In addition, there are three characteristics which define the aesthetic value of makizushi taste; unity, harmony and contrast.
\end{abstract}

Keywords : Aesthetic value, Food Aesthetic, Sushi, maki-zushi, Tv Champion Japan

Jepang kaya akan hasil bahan makanan yang berasal dari pegunungan, sungai dan lautnya, hal ini menjadikan Jepang kaya akan berbagai macam makanan yang unik dan menarik untuk disantap. Dimulai dari berbagai resep yang menonjolkan kesegaran dari bahan makanan yang digunakan, cara pengolahan yang berusaha menggunakan alam sebagai metode pengawetan, termasuk antusiasme masyarakat Jepang dalam menyerap berbagai resep asing yang masuk ke Jepang. Peralatan makan yang beragam ukuran dan motif juga menjadi pendukung dalam penyajian makan di Jepang, termasuk penyajian makanan itu sendiri ditata dengan sudut pandang keindahan (Ishige Naomichi, 2006:4).

Negara Jepang secara tidak langsung membuat peraturan bahwa dalam penyajian suatu makanan, berusaha untuk menampilkan lima kombinasi warna yang berkaitan dengan alam, yaitu warna merah, kuning, hijau, coklat dan hitam. Seorang 
Theng Anita Christianawati, Nilai Estetika dan Cita Rasa Makanan dalam Penyajian Makizuki Musim Gugur pada TV Champion Jepang

koki berusaha untuk menggabungkan warna-warna tersebut menjadi hidangan yang menawarkan keindahan, yang entah bagaimana caranya, mampu menjadi sebuah makanan yang juga bergizi (Otani Hiromi, 2006:10).

Makanan Jepang disajikan agar mampu sedekat mungkin sesuai dengan keadaan alaminya, dan keserasian warna, aroma maupun rasa. Bumbu-bumbu yang digunakan juga menjadi perhatian khusus dalam menyajikan sebuah makanan Jepang, termasuk kapan waktu atau musim yang tepat untuk menyajikan hidangan tersebut. Penyajian suatu hidangan juga tidak lepas dari permainan bentuk dan warna yang digunakan serta pemilihan bahan yang tepat sesuai dengan musim dan menu sampingan lainnya.

Salah satu makanan khas negara Jepang yang menonjolkan keindahan dan kelezatannya, adalah sushi. Pada awalnya, sushi adalah salah satu cara untuk mengawetkan makanan terutama ikan segar yang memang menjadi pusat makanan di Jepang. Namun, seiring berkembangnya waktu, sushi menjadi sebuah makanan khas yang menonjolkan kelezatan dalam penyajiannya yang singkat sekaligus kerumitan di balik rasanya yang memikat tersebut.

Ada bermacam-macam jenis sushi yang ada di Jepang. Jenis sushi tersebut pada umumnya dibedakan menurut musim yang ada di Jepang dan menurut suatu daerah yang menonjolkan hasil tangkapan laut di daerah tersebut. Cara pengolahannya pun tidak semudah yang terlihat. Setiap bagian negara Jepang memiliki resep tersendiri sesuai dengan kondisi yang ada di bagian wilayah tersebut, dan biasanya memiliki tradisi kuno yang berlaku dalam pengolahan suatu bahan sehingga mampu menghasilkan hidangan yang memikat. Sushi menjadi sebuah lambang mengenai tradisi kuno yang berusaha dipertahankan oleh masyarakat Jepang modern ini. Oleh karena itu, sushi menjadi raja dari makanan khas negara Jepang, dan tentunya pantas mendapat penghargaan tersebut (Kuniko, 2006:18-19).

Seiring berkembangnya waktu, orang-orang di berbagai belahan dunia tertarik untuk mencicipi sekaligus mempelajari cara pembuatan sushi yang unik dan penuh dengan rahasia-rahasia yang terus dijaga turun-temurun hingga saat ini. Cara 
penyajiannya pun tak luput menjadi hal penting yang harus diperhatikan ketika membuat sushi, baik dari komposisi rasa maupun ukuran penyajian yang disajikan dengan ukuran yang tidak terlalu besar namun pas ketika dimakan dalam sekali suapan, misalnya makizushi yang tidak terlalu banyak isian, menjadikan gulungannya tidak terlalu besar dan dapat dimakan dalam sekali suapan. Sehingga hanya dalam sekali suapan saja dapat terasa seluruh isian yang digunakan dalam makizushi tersebut. Hal ini membuat penulis tertarik untuk mengambil tema ini.

\section{METODE}

Jenis penelitian yang digunakan penulis adalah jenis penelitian deskriptif kualitatif. Penelitian ini bersifat deskriptif karena mendeskripsikan tentang keindahan dalam penyajian dan cita rasa makanan terutama dalam penyajian sebuah hidangan makizushi. Penelitian ini disebut kualitatif karena hasil penelitian ini disampaikan dalam bentuk kata-kata, yang menunjukkan tentang keindahan yang ada dalam penyajian hidangan makizushi tersebut. Selain itu, penelitian ini juga merupakan penelitian pustaka. Dalam hal ini, sumber literatur tertulis seperti jurnal dan artikel juga digunakan sebagai data pada penelitian ini.

Sumber data utama dalam penelitian ini berupa sebuah video acara reality show yang berjudul "TV Champion Japan" seri pertama dengan judul episode Sushi King. Video ini dibuat oleh TV Tokyo Japan, yang berdurasi sekitar 70 menit. Penulis memilih video ini, dikarenakan video ini mampu mewakili permasalahan yang penulis teliti mengenai pembuatan makizushi dengan konsep musim gugur, dan menonjolkan keindahan dalam penyajiannya.

Teknik pengumpulan data yang penulis gunakan untuk meneliti video reality show TV Champion Jepang ini, yaitu mencari video-video mengenai TV Champion Jepang di internet mengenai makanan termasuk sushi. Kemudian menonton video tersebut dan menuliskan setiap dialog yang diucapkan dalam video tersebut. Tahap berikutnya memeriksakan hasil skrip yang didengar kepada native speaker dan menterjemahkan skrip tersebut ke dalam bahasa Indonesia. Selanjutnya mengelompokkan data sesuai dengan kriteria keindahan yang digunakan sebagai 
Theng Anita Christianawati, Nilai Estetika dan Cita Rasa Makanan dalam Penyajian Makizuki Musim Gugur pada TV Champion Jepang

acuan.

Teknik-teknik yang digunakan dalam pengumpulan data dalam penelitian ini adalah penulis menampilkan data yang akan dianalisis. Data tersebut berupa potongan gambar dan dialog yang menunjukkan penggambaran mengenai keindahan penyajian suatu makanan. Kemudian mendeskripsikan data sesuai dengan dialog dan gambar. Selanjutnya menginterpretasikan data tentang penggambaran keindahan penyajian hidangan sushi tersebut. Yang terakhir adalah penarikan simpulan berdasarkan data yang telah dianalisis.

\section{PEMBAHASAN}

Pembahasan data-data yang menunjukkan adanya nilai keindahan dalam suatu penyajian makizushi.

\section{1. makizushi yang disajikan perporsi}

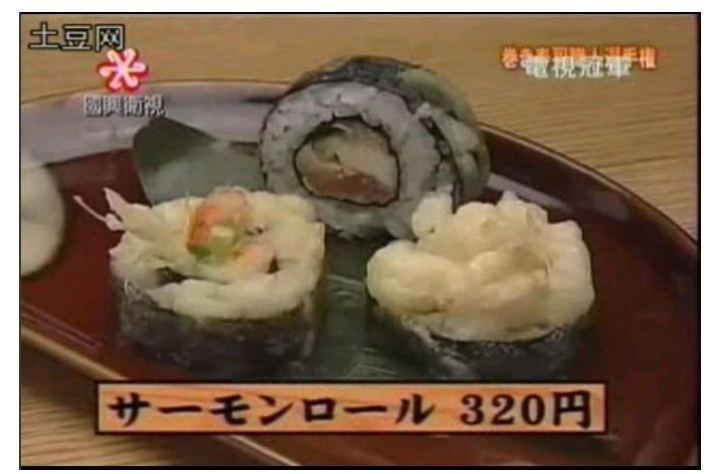

Gambar 1, salmon roll yang dibuat oleh Miyao

\section{宮應}

: あぶることによって、生で食べるのと違った香ばしさが出て旨 味が出るんです。技の福兆の技の由来であります。

Miyao : Abura koto ni yotte, nama de taberu noto chigatta koubashisa ga dete umami ga derun desu. Waza no fukuchou no waza no yurai de arimasu.

Miyao : Akan berbeda jika dipanggang dan dimakan mentah. Setelah aromanya keluar, kelezatan akan keluar. Itulah asal-usul Teknik Beribu Kebahagian.

なかでも人気なのがあぶった鮭の巻き寿司を丸ごとあげたサーモ ンロール。外はサク、中はジュワー。これぞ細工を得意とする宮 應の真骨頂だ。

Nakademo ninki nanoga abutta sake no makizushi o marugoto ageta saamon rooru. Soto wa saku, naka wa juwaa. Kore zo saiku o tokui to 
suru Miyaou no shinkocchou da.

Yang popular dari buatannya adalah makizushi ikan salmon panggang yang mirip gulungan ikan salmon goreng. Luarnya renyah, dalamnya ketika dimakan seperti ada kuah yang keluar. Di situlah sebenarnya inti dari kehebatan dari Miyao.

Kalimat dan gambar pada data ketiga ini, diucapkan pada menit ke 00:03:08. Gambar 1 merupakan hasil karya dari Miyao yang diberi nama "Salmon Roll" yang dipraktikkan langsung saat ia sedang diwawancarai oleh pihak Tv Champion. Begitu pula dengan kalimat yang ada dibawah gambar 1 tersebut diucapkan pada saat Miyao mempraktekkan salah satu menunya yang bernama salmon roll di restoran yang dikelolanya. Ia menjelaskan bagaimana perbedaan rasa yang muncul ketika ikan tersebut dimakan dalam keadaan segar atau setelah dipanggang. Sehingga disinilah letak kehebatan dari Miyao mengenai cara pengolahan yang berbeda, sehingga menghasilkan rasa yang luar biasa ketika dinikmati, walaupun dari penampakan luar hanya terlihat sederhana seperti yang terlihat pada gambar 1 .

Berdasarkan data yang ada pada data ketiga ini, sisi keutuhan rasa dapat dipahami melalui kalimat「外はサク、中はジュワー」(Soto wa saku, naka wa juwaa), yang berarti bahwa keutuhan rasa diperoleh dengan perpaduan yang sama kuat antara rasa renyah pada lapisan luarnya dengan rasa lembut di bagian dalam yang beradu menjadi sebuah kesatuan yang unik dan nikmat ketika dinikmati dalam sekali suapan. Sedangkan keselarasan rasa didapat melalui perpaduan rasa renyah dan lembut menjadi suatu perpaduan yang cocok dan saling melengkapi satu sama lain. Begitu pula untuk sisi kekontrasan rasa terlihat pada cara Miyao lebih menonjolkan rasa dari ikan yang dipanggang, yang rasanya menjadi lebih nikmat dibandingkan rasa ketika ikan tersebut dimakan dalam keadaan mentah.

Begitu pula dengan sisi keutuhan dari segi warna yang ada pada gambar 1 menunjukkan bahwa adanya komposisi warna yang seimbang dan sangat menyatu ditiap unsurnya seperti warna pada makizushi yang cenderung agak pucat dengan perpaduan warna putih dari nasi dan warna putih tulang pada kulit dan isiannya, juga sedikit warna hijau dan merah pucat pada bagian dalam makizushinya disatukan dengan piring yang berwarna merah bata menjadikan hidangan tersebut terlihat menyatu dengan warna yang terlihat lebih menarik. 
Theng Anita Christianawati, Nilai Estetika dan Cita Rasa Makanan dalam Penyajian Makizuki Musim Gugur pada TV Champion Jepang

Hidangan pada gambar 1 juga menunjukkan keselarasan warna antara warna pada makizushi dengan warna pada piring yang digunakan sehingga terlihat cocok dan saling mendukung satu dengan yang lain. Keselarasan warna pada gambar 1 juga membuat nyaman untuk dilihat dan tidak mencolok sehingga menarik minat konsumen untuk mencobanya. Sedangkan sisi kekontrasannya terlihat dari penggunaan piring yang berwarna merah digabungkan dengan makizushi yang berwarna putih dan hitam, meskipun warna hitam dan merah memiliki kekuatan- asal yang kuat tetapi keduanya disatukan dan dinetralkan dengan warna putih dari makizushi dan warna hijau pada garnishnya, menjadi perpaduan warna yang unik dan menarik. Sehingga keseimbangannya pun terlihat pada penyajiannya yang berusaha menggabungkan warna-warna alami dengan porsi yang sama dan menjadi kesatuan yang menarik dipandang mata.

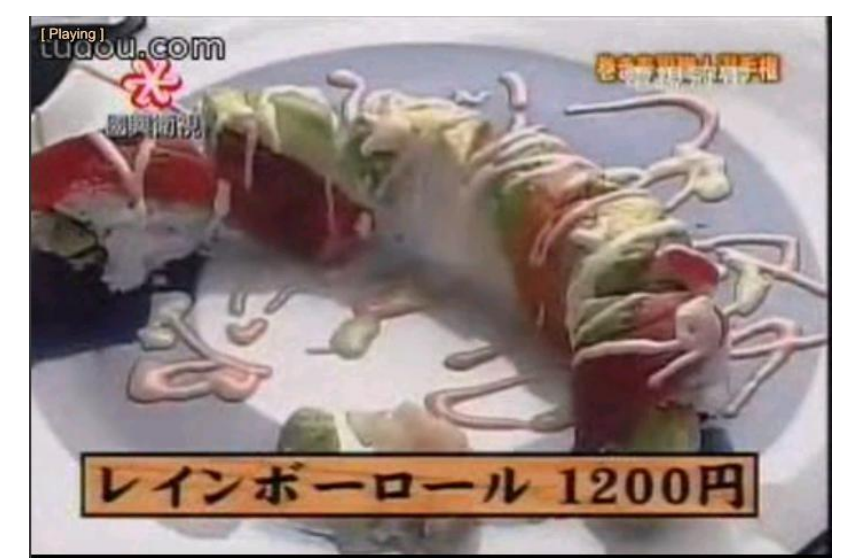

Gambar 2, rainbow roll yang dibuat oleh Sugeta

同じく乗り物を作るのは

ローリングアーティスト、菅田勇樹。大田区にある高砂寿司はい つも地元のお客さんでいっぱい。人気の秘密はその新鮮なネタと 職人菅田の腕。伝統の技が光る。さらに菅田はアメリカに渡りイ ンターナショナルな寿司を逆輸入。アメリカが帰りの感性で作る 巻き寿司はカラフルなネタで彩る寿司ロール。サーモン、マグロ 、アボカドを梅マヨネーズソースで食べる、その名もレインボー ロール。その豊かな発想で 遊びの心ある巻き寿司を作り続けている。

Onajiku norimono o tsukuru nowa rooringu aatisuto, Sugeta Yuuki. Ootaku ni aru Takasago makizushi wa itsumo jimoto no okyakusan de ippai. Ninki no himitsu wa sono shinsenna neta to shikunin Sugeta no 
ude. Dentou no waza ga hikaru. Sarani Sugeta wa Amerika ni watari intaanashonaruna makizushi o gyakuyunyuu. Amerika ga kaeri no kanjou de tsukuru maki wa karafuru na neta de irodoru makizushi rooru. Saamon, maguro, abokado o ume mayoneezu soosu de taberu. Sono mei mo reiboo rooru. Sono yutakana hasso de asobi no kokoro aru makizushi o tsukuri tsuzukete iru.

Yang juga sama membuat kendaraan adalah seniman bergulir, Sugeta Yuuki. Takasago makizushi yang ada di daerah Oota selalu penuh dengan pembeli dari daerah sekitarnya. Rahasia dari kepopulerannya adalah kemampuannya dan bahan-bahan yang segar. Teknik tradisional yang terkenal. Selain itu Sugeta sudah mengimpor balik ke Jepang melalui Amerika makizushi internasional. Makizushi yang dibuatnya dengan perasaan yang didapat setelah pulang dari Amerika berupa gulungan makizushi yang penuh dengan bahan-bahan berwarna. Makan ikan salmon, ikan tuna, alpukat dengan mayones dan saus buah plum. Namanya juga gulungan pelangi. Dengan keberagaman pikiran tersebut , ia terus berusaha membuat kreasi makizushi sesuai dengan ide yang ia ciptakan.

Gambar dan kalimat pada data keenam ini diambil pada menit ke 00:11:30 pada saat narator menjelaskan mengenai profil kontestan lomba yang selanjutnya yaitu Sugeta Yuuki. Sugeta mengelola sebuah kedai makizushi yang bernama takasago makizushi yang setiap harinya selalu penuh dengan pembeli. Sugeta pernah tinggal di Amerika untuk beberapa waktu, hingga kemudian ia kembali ke Jepang dan mengadaptasi makizushi ala Amerika sehingga disinilah letak rahasia dari kedai makizushi yang dikelola oleh Sugeta. Gambar 2 adalah salah satu contoh makizushi yang dibuat oleh Sugeta, yang diberi nama rainbow roll, yang bermakna gulungan pelangi dengan warna-warni dari bahan yang diletakkan diatas gulungan nasi tersebut, yang menjadi salah satu hidangan andalannya.

Berdasarkan gambar dan kalimat pada data keenam ini, sisi keutuhan rasa dapat terlihat pada cara Sugeta dengan ahli mencampurkan bahan-bahan yang segar dengan komposisi yang sama sehingga mampu menghasilkan rasa yang menyatu dan enak meskipun masing-masing bahan memiliki rasa asli yang berbeda- beda. Dari segi keselarasannya pun dapat tergambar melalui perpaduan rasa dari bahan-bahan yang digunakan saling melengkapi sehingga menimbulkan rasa yang lezat ketika dimakan. Misalnya saja, rasa dari ikan salmon dan ikan tuna segar jika ditambahkan dengan rasa creamy dari alpukat dan saus mayones serta rasa gurih dari nasi yang 
Theng Anita Christianawati, Nilai Estetika dan Cita Rasa Makanan dalam Penyajian Makizuki Musim Gugur pada TV Champion Jepang

telah diberi cuka akan terasa sangat cocok dan saling melengkapi ketika dimakan.

Begitu pula dari segi penampilan, yang diperkuat dengan kalimat 「アメリカが帰りの感性で作る巻き寿司はカラフルなネタで彩る寿司ロール 。サーモン、マグロ、アボカドを梅マヨネーズソースで食べる、その名もレ インボーロール」 (Amerika ga kaeri no kanjou de tsukuru maki wa karafuru na neta de irodoru makizushi rooru. Saamon, maguro, abokado o ume mayoneezu soosu de taberu. Sono mei mo reiboo rooru) yang berarti bahwa setelah kepulangannya dari amerika, ia seperti mendapat inspirasi baru sehingga ia membuat gulungan makizushi dengan lebih bermain pada warna-warni bahan yang ada, seperti warna- warna alami dari bahan-bahan segar seperti ikan tuna, ikan salmon, alpukat dan warna-warna alami dari bahan-bahan lainnya. Sehingga sisi keutuhan terlihat dari warna-warna asli pada bahan diletakkan berdampingan dan terlihat saling melengkapi dengan variasi warna yang menarik. Misalnya saja yang terlihat seperti pada gambar 2, warna putih dari nasi yang terlihat sederhana divariasikan dengan ikan salmon yang berwarna merah cerah berdampingan dengan warna merah pekat dari ikan tuna dan dinetralkan dengan warna kuning kehijau-hijauan dari alpukat menjadikan makizushi tersebut terlihat menarik dengan variasi warna yang ada.

Sedangkan sisi keselarasan terlihat dari warna-warna yang ada di lapisan atas makizushi disusun menjadi sebuah kesatuan yang terlihat cocok dan terpadu dengan irisan yang serupa, sehingga hidangan tersebut terlihat menarik serta nyaman dipandang mata karena warna-warna dasar dari bahan yang terlihat menonjol dinetralkan dengan warna-warna dari bahan lain, seperti warna merah yang menonjol dari bahan ikan tuna dinetralkan dengan warna kuning kehijau- hijauan dari alpukat disampingnya. Sisi keseimbangan yang berkaitan dengan kesimetrisannya terlihat dari cara irisan bahan yang diletakkan diatas gulungan nasi terlihat serupa dengan bentuk yang tipis memanjang, termasuk jika hidangan tersebut dibelah menjadi dua bagian pun, bagian yang pertama mampu menjadi cerminan dari bagian yang lainnya sehingga tergolong dalam kondisi simetris.

Sedangkan sisi kekontrasannya ditunjukkan melalui penonjolan warna- warni dari bahan-bahan yang ada dibagian atas gulungan nasi tersebut. Karena gulungan nasi yang berwarna putih dengan warna piring yang juga putih terlihat sederhana dan 
pucat sehingga dengan pemberian aneka warna dari bahan-bahan yang diletakkan diatas gulungan nasi tersebut, makizushi yang ada menjadi terlihat lebih menarik dengan penonjolan warna-warna tersebut. Oleh karena itulah hidangan ini diberi nama rainbow roll atau gulungan pelangi.

\section{Makizushi yang disajikan secara bucket}

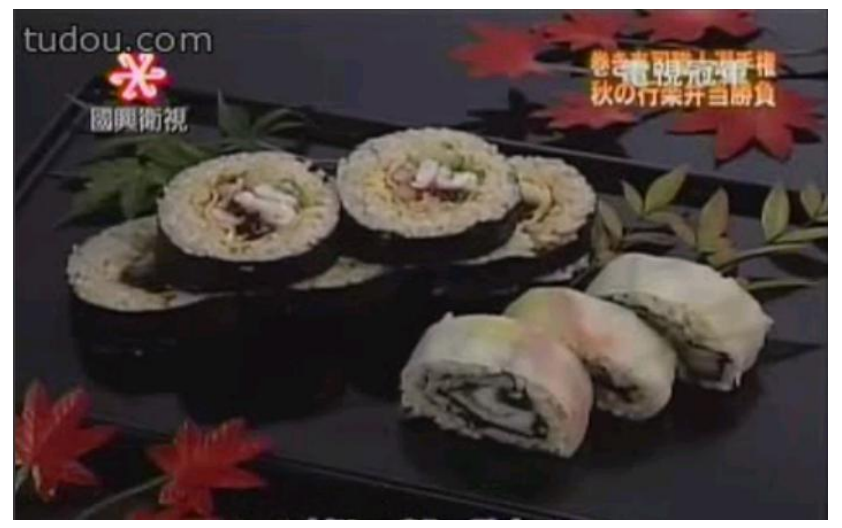

Gambar 2 makizushi bentou yang dibuat oleh Takano

玄米を昆布の出汁じるで炊きあげればうまみと豊かな香りがたっぷ り。それにあわせるのは関西ならではの素材、ハモ。見て食べて秋 を喫す

る。そんな巻き寿司弁当をイメージ。玄米の素朴な味わい、のりの 何ともよい香り。中に巻きこむのは八モとエリンギ心地良い食感。 赤く色付く木々、澄み渡る空気。大根の桂剥きの中に、そんな日 本の秋の味と美しい風景を閉じ込めた。ほんのり透けて見えるパ プリカとトマトの色味に誘われてーロ頬張れば、舌に広がる日本 の秋。関西ならではの味と風景にこだわった、高野の『秋味』。 穴子や煮詰め豆腐などを巻いたにんにく巻きがこれまた風流。大 人の巻き寿司弁当となった。

Genmai o konbu no dashijiru de taki agereba umami to yutakana kaori ga tappuri. Sore ni awaseru no wa kansai nara de wa no sozai, hamo. Mite tabete aki o kitsusuru. Sonna makizushi bentou o imeji. Genmai no soboku na ajiwai, nori no nani to mo yoi kaori. Naka ni maki komu no wa hamo to eringi kokochi yoi shokukan. Akaku irozuku kigi, sumi wataru kuuki. Daikon no katsuramuki no naka ni, sonna nihon no aki no aji to utsukushii fuukei o tojikometa. Honnori sukete mieru papurika to tomato no iromi ni sasowarete hito kuchi hoobareba, shita ni hirogaru nihon no aki. Kansai nara de wa no aji to fuukei ni kodawatta, takano no "aki aji”. Anago ya nitsume toufu nado o maita ninniku maki ga kore mata 
Theng Anita Christianawati, Nilai Estetika dan Cita Rasa Makanan dalam Penyajian Makizuki Musim Gugur pada TV Champion Jepang

fuuryuu. Otona no makizushi bentou to natta.

Genmai ${ }^{1}$ yang direbus dengan kaldu konbu ${ }^{2}$ akan menjadikan rasa enak dan penuh dengan aroma yang bervariasi. Selain itu, yang dipadukan dengannya adalah hamo dari Kansai. Dengan melihatnya, memakannya maka akan merasakan musim Gugur. Dia akan membuat gambaran bento makizushi yang seperti itu. Rasa yang alami dari genmai, aroma yang benar-benar tak terlukiskan dari nori. isi gulungannya adalah hamo dan eringi $i^{3}$ menjadikan perasaan makan yang menyenangkan.

Udara bersih yang melewati pepohonan yang kemerahan, pemandangan yang indah dan rasa musim gugur seperti itu akan masuk dan tertutup oleh irisan tipis dari lobak. Warna sedikit tomat dan paprika yang terlihat menempel, mengundang untuk mencicipinya, dan jika mencoba seluruh lidah akan merasakan musim gugur Jepang. Itu menjadi hal yang memikat rasa dan pemandangan di Kansai. "Rasa Musim Gugur Takano". Cita rasa yang terkandung didalam gulungan bawang putih yang digulung dengan belut, tahu rebus, dan lain-lain menjadi bento makizushi untuk orang dewasa.

Gambar dan kalimat pada data 2 ini diambil pada menit ke 00:21:31 ketika narator menjelaskan mengenai makizushi yang dibentuk menjadi bentou yang dibuat oleh Takano. Takano membuat makizushi bentou yang diberi nama『秋味』(aki aji), yang dimaksudkan agar rasa dari musim gugur dapat tergambarkan pada makizushi bentou yang telah ia buat. Takano membuat dua hidangan yang bervariasi, yang pertama menggunakan genmai yang direbus dengan kaldu, kemudian dipadukan dengan hamo dan eringi. Hidangan yang kedua menggunakan bermacam- macam bahan seperti irisan lobak, tomat, paprika, belut, tahu rebus dan bahan- bahan lain yang menjadikan makizushi tersebut kaya akan rasa yang beragam dan beradu di dalam mulut ketika dimakan. Kedua hidangan yang dibuat oleh Takano ini dianggap mampu mewakili rasa musim gugur yang menjadi tema dalam perlombaan kali ini.

Pada hidangan yang pertama, sisi keutuhan rasa ditunjukkan pada kalimat

「玄米を昆布の出汁じるで炊きあげればうまみと豊かな香りがたっぷり」

1. 1玄米 genmai adalah beras yang berwarna kecoklatan dan mengandung banyak serat. Beras ini juga memiliki lebih banyak kandungan vitamin dan mineral dibandingkan dengan beras putih yang sering dijumpai sehari-hari.

2. 昆布 konbu adalah sejenis rumput laut yang juga dapat digunakan untuk membungkus sushi. 
3. 3 エリンギ eringi adalah jenis jamur yang dapat dimakan dengan cara diolah terlebih dahulu seperti ditumis, direbus, digoreng atau dimasukkan ke dalam sup. Jamur jenis ini akan menyebabkan keracunan jika dimakan dalam keadaan mentah. Jamur ini memiliki tekstur yang kenyal dan beraroma khas ketika diolah menjadi suatu hidangan. 
Theng Anita Christianawati, Nilai Estetika dan Cita Rasa Makanan dalam Penyajian Makizuki Musim Gugur pada TV Champion Jepang

(Genmai o konbu no dashijiru de taki agereba umami to yutakana kaori ga tappuri), juga pada kalimat

\section{「玄米の素朴な味わい、のりの何ともよい香り。中に巻きこむのは八モとエ} リンギ心地良い食感」(Genmai no soboku na ajiwai, nori no nani to mo yoi kaori. Naka ni maki komu no wa hamo to eringi kokochi yoi shokukan), yang berarti bahwa rasa alami dari genmai yang direbus dengan kaldu lalu disatukan dengan nori, hamo, dan eringi menjadi sebuah variasi hidangan yang menarik untuk dicicipi. Juga aroma yang tercipta dari perpaduan bahan-bahan tersebut membuat siapapun yang melihatnya tertarik untuk mencobanya karena dari aromanya pun sangat kaya dan membuat penikmat semakin penasaran bagaimana rasa dari makizushi tersebut.

Rasa alami dari genmai yang direbus dengan kaldu konbu dipadukan dengan rasa dari nori, hamo dan eringi menjadi suatu kesatuan rasa yang cocok dan terasa harmonis ketika dimakan, seperti yang diungkapkan pada kalimat 「中に巻きこむのはハモとエリンギ心地良い食感」(Naka ni maki komu no wa hamo to eringi kokochi yoi shokukan), sehingga dengan memakan makizushi buatan Takano ini akan menimbulkan perasaan yang menyenangkan bagi penikmatnya. Tidak hanya rasa lezat di lidah saja, namun rasa nyaman dan senang juga dirasakan di dalam hati setiap penikmatnya. Sehingga inilah hal yang ingin ditonjolkan oleh seorang Takano dari salah satu hidangan makizushi buatannya, yaitu rasa enak yang dapat dirasakan di lidah ketika memakannya, maupun rasa enak atau nyaman di dalam hati saat memakan ataupun sesudah memakan makizushi ini.

Pada hidangan yang kedua, sisi keutuhan rasa terlihat dari banyaknya bahan yang digunakan Takano, yaitu lobak, tomat, belut, tahu rebus dan bahan-bahan lainnya, yang sangat bervariasi namun mampu melebur menjadi satu kesatuan rasa yang nikmat ketika dimakan. Keselarasan rasa yang tercipta dari perpaduan bahanbahan tersebut menjadi suatu perpaduan yang cocok dan nyaman ketika dimakan bersamaan dalam sekali suapan, meskipun ada banyak sekali variasi rasa yang timbul dari masing-masing bahan yang dimasukkan di dalam gulungan makizushi tersebut. Sehingga inilah hal yang ingin ditonjolkan oleh Takano dalam hidangan makizushi nya yang kedua ini, yaitu perpaduan rasa dari banyaknya bahan yang ada menjadi 
sebuah rasa yang sangat kaya dan nikmat, meskipun hanya dalam sekali suapan.

Sedangkan sisi keutuhan warna yang ada pada gambar 2 ini, terlihat pada komposisi warna yang beragam namun menjadi sebuah kesatuan yang terlihat menyatu baik dari warna hitam pada piring maupun pada nori yang membalut gulungan salah satu hidangan makizushi tersebut, juga warna putih, dengan perpaduan warna yang ada ditengah gulungan setiap makizushi menjadikan hidangan makizushi bentou yang dibuat oleh Takano ini menyatu dengan berbagai variasi warna yang ada di setiap gulungan makizushinya. Sehingga terlihatlah keselarasan warna pada hidangan yang ada pada gambar 2 ini, perpaduan warna dari setiap bahan yang digunakan terlihat cocok dan saling melengkapi dan terciptalah perpaduan warna yang indah dan nyaman untuk dilihat. Misalnya saja warna hitam yang berasal dari piring dan nori memiliki kekuatan-asal warna yang kuat, dilengkapi dengan gulungan makizushi yang berwarna putih dan cenderung menggunakan bahan-bahan berwarna cerah lainnya seperti warna merah pada tomat dan paprika, ditambah dengan beberapa lembar daun momiji yang berwarna merah dan hijau yang diletakkan disekitar gulungan makizushi tersebut, menjadi sebuah keharmonisan warna yang menarik.

Keselarasan warna tersebut juga berhubungan dengan keseimbangan warna yang digunakan agar tetap terlihat harmonis dan menyatu antar warna-warna yang ada. Jika warna hitam lebih banyak digunakan, maka hidangan tersebut akan terkesan membosankan dan tidak menarik untuk dicicipi karena kekuatan-asal warna hitam yang terlalu kuat. Terlebih lagi, keseimbangan warna ini berkaitan dengan penempatan diri terhadap alam, bagaimana hidangan ini dapat sedekat mungkin dengan keadaan alam yang sesungguhnya, melalui warna yang ada. Jika keadaan di alam yang sesungguhnya memiliki warna-warna yang beragam, maka hidangan ini pun juga menggunakan warna yang beragam, misalnya warna putih, kuning, hijau, merah dan hitam yang juga mewakili warna dari alam yang sesungguhnya. Ditambah dengan penggunaan daun momiji yang asli menjadikan hidangan ini sangat mewakili keadaan alam yang sesungguhnya dan sesuai dengan tema yang sedang diperlombakan. 
Theng Anita Christianawati, Nilai Estetika dan Cita Rasa Makanan dalam Penyajian Makizuki Musim Gugur pada TV Champion Jepang

Oleh karena itu, dapat dipahami bahwa hal yang ingin ditonjolkan Takano dalam kekontrasan warna pada hidangannya ini adalah perpaduan warna yang ada di setiap gulungan makizushinya yang mewakili warna dari tiap bahan yang digunakan, sehingga terlihatlah betapa banyaknya variasi bahan yang digunakan dan betapa kayanya rasa yang tercipta dari hidangan yang ada pada gambar 4.2.1 ini.

\section{SIMPULAN}

Berdasarkan penelitian yang telah dilakukan mengenai nilai estetika yang terkait pada penyajian makizushi dalam TV Champion Jepang, ditemukan bahwa dalam suatu penyajian makizushi tidak hanya cita rasa yang menjadi perhatian dalam pembuatannya namun juga bagaimana suatu hidangan makizushi tersebut mampu menampilkan warna-warni yang menarik dan menggugah selera. Dalam penyajian makizushi pada umumnya terdapat beberapa ciri-ciri umum yang menjadi acuan mengenai suatu hasil penyajian makizushi tersebut dapat dikatakan indah, yaitu kesatuan atau keutuhan, kesimetrisan, keselarasan, keseimbangan dan kekontrasan atau penonjolan. Namun, dari segi keindahan cita rasa, hanya tiga ciri yang mampu diterapkan agar hidangan tersebut bisa dikatakan indah dari segi cita rasa yang ada yaitu sisi kesatuan rasa, keselarasan rasa dan kekontrasan rasa.

\section{REFERENSI}

(producer), T. T. (n.d.). TV Champion Japan: Sushi King (Reality Show).

Djelantik, A. (1999). Estetika sebagai pengantar. Bandung: Masyarakat Seni Pertunjukan Indonesia.

Gakken. (1990). Japan As It Is (2nd ed.). Tokyo: Author.

Gie, T. L. (1983). Garis Besar Estetik (Filsafat keindahan). Yogyakarta: penerbit supersukses.

Hiromi, O. (2006, maret 15). Nipponia. Seni yang Menarik: Peralatan dan Penyajian Makanan, p. 10.

Kuniko, S. (2008, Desember 15). Nipponia. Sushi Archipelago Local Specialties, pp. 18-19. Matsura, K. (1994). Kamus Bahasa Jepang-Indonesia. Kyoto: Kyoto 
Sangyo University Press.

Merriam-webster, I. (2000). Merriam-webster's Collegiate Encyclopedia. USA: Library of Congress Cataloging.

Naomichi, I. (2006, maret 15). Nipponia. Makanan: Pandangan Lain tentang Sejarah Budaya Jepang , p. 4.

Ratna, N. K. (2007). Estetika Sastra dan Budaya. Yogyakarta: Pustaka Pelajar.

Sugimoto, Y. (2009). The Cambridge Companion to Modern Japanese Culture. Australia: Cambridge University Press.

Sutrisno, M., \& Verhaak, C. (1993). Estetika Filsafat Keindahan. yogyakarta: penerbit kanisius.

\section{Website :}

www.jisho.org

Azhar, E.F.(2008, juli 11). Retrieved from lib.ui.ac.id: http://lib.ui.ac.id/file?file=digital/20160237-RB08A528n-Nilainilai\%20estetika.pdf) (diakses pada 11 Februari 2015)

Azmy, F. (2011, agustus 20). sushi. Retrieved from USU Institutional Repository: http://repository.usu.ac.id/handle/123456789/28602 (diakses pada 11 Februari 2015)

Carroll, W. F. (2009, maret 31). SUSHI: Globalization through Food Culture:Towards a Study of Global Food Networks. Retrieved from Kansai University Institutional Repository: $\quad$ http://kuir.jm.kansaiu.ac.jp/dspace/handle/10112/3253 (diakses pada 10 Februari 2015)

Eating Seasonal Food: The Japanese Way. (2011, September 4). Retrieved from All in Japan: http://www.allinjapan.org/eating-seasonal-food-the-japanese-way/

Satterwhite, R. (n.d.). Sushi Vocabulary. Retrieved from bentou.com: http://www.bento.com/sushivoc.html (diakses pada 8 Maret 2015)

Silalahi, E. N. (2010, Januari 30). Nilai-nilai Ajaran Zen Buddhisme dalam Estetika Keramik Tradisional Jepang. Retrieved from USU Institutional Repository: http://repository.usu.ac.id/handle/123456789/13477 (diakses pada 12 Februari 2015) 